\section{Association between metabolic syndrome and parameters of 24-hour blood pressure ambulatory monitoring}

\author{
Associação entre síndrome metabólica e parâmetros da \\ monitorização ambulatorial da pressão arterial de 24 horas
}

Mariana Santos Felisbino-Mendes' , Tatiane Géa-Horta' Antônio Luiz Pinho Ribeiro², Gilberto $\mathrm{Kac}^{3}$, Salete Maria de Fátima Silqueira', Gustavo Velásquez-Meléndez'
${ }^{1}$ Nursing School, Universidade Federal de Minas Gerais (UFMG), Belo Horizonte, MG, Brazil ${ }^{2}$ Hospital das Clínicas, UFMG, Medical School, Belo Horizonte, MG, Brazil ${ }^{3}$ Nutrition Institute, Universidade Federal do Rio de Janeiro (UFRJ), RJ, Brazil

\title{
RESUMO
}

Objetivo: Investigar associação entre síndrome metabólica (SM) e parâmetros da monitorização da pressão arterial de 24 horas (MAPA) como medida de risco cardiovascular (RCV). Sujeitos e métodos: Foram estudados 136 pacientes hipertensos, ambos sexos, idade entre 29 e 83 anos. RCV foi definido pela presença de, no mínimo, três das seguintes condições: 1) pressão arterial sistólica/diastólica $\geq 140 / 90 \mathrm{mmHg}$, ausência/atenuação do descenso noturno e pressão de pulso (PP) $\geq 53 \mathrm{mmHg}, 2$ ) pressão de pulso 24h (PP24h), 3) sono (PPS), 4) vigília (PPV) e 5) descenso noturno. Resultad os: PPV, PPS e PP24h estiveram aumentadas em $54 \%$ dos pacientes. Hipertrigliceridemia (52\%), HDL baixo (72,8\%), obesidade abdominal $(60,3 \%)$, SM $(58,1 \%)$, dislipidemia $(88,8 \%)$, sobrepeso $(74,3 \%)$ e obesidade $(33,8 \%)$ estavam elevados. SM, ajustada pela idade, foi associada a elevado RCV (OR = 4,5 e OR =3,6), a PP24h (OR =2,3 e OR $=4,7)$ e a PPS (OR $=2,2$ e OR $=4,6)$. Conclusões: SM foi altamente prevalente e correlacionada aos parâmetros da pressão arterial de 24 horas alterados. Arq Bras Endocrinol Metab. 2011;55(6):383-8

Correspondence to: Gustavo Velásquez-Meléndez Universidade Federal de Minas Gerais, Escola de Enfermagem Av. Alfredo Balena, 190 30130-100 - Belo Horizonte, MG, Brazil

guveme@ufmg.br

Received on Sep/4/2010 Accepted on Jun/3/2011 


\section{INTRODUCTION}

$\mathrm{E}$ vidence has shown that blood pressure (BP) measurements obtained during a 24-hour period by means of ambulatory blood pressure monitoring (ABPM), especially BP measured during sleep, are better predictors of cardiovascular events (such as myocardial infarction and cerebral vascular accident, including target organ damage) than sporadic BP measurements taken at the physician's office (1-5).

This predictive ability is related to several factors, such as the possibility of identifying individuals with white-coat or masked hypertension. Thus, narrow variations in BP during nighttime and daytime have high prognostic power for clinical outcomes. Some studies revealed greater probability of target organ damage in the absence of at least $10 \%$ drop in BP between daytime and nighttime periods (6-10).

Another important prognostic marker in individuals older than 55 years of age is pulse pressure (PP). In a study conducted on 2,010 patients, it was observed that the occurrence of cardiovascular events was $19 \%$ and $81 \%$ greater in the second and third tertiles of 24 hour BP measurements than in the first tertile (11).

The objective of the present study was to estimate the associations between metabolic syndrome (MS) and 24-hour blood pressure measurements in a sample of hypertensive subjects in a Health Care Center of Belo Horizonte, Brazil.

\section{SUBJECTS AND METHODS}

This was a cross-sectional study conducted in outpatient practice for hypertensive patients treated at the Hospital das Clínicas, Universidade Federal de Minas Gerais, and linked to programs on education, self-care, control, and secondary prevention of disease, and to the Family Health Program in the city of Belo Horizonte, in Brazil.

All patients from the programs cited above were invited to participate in this study. At the end of recruitment period, the sample was composed of 136 patients aged between 29 and 83 years old, of both sexes, who were undergoing regular monitoring by these programs. They also had clinical diagnosis of arterial hypertension confirmed by physicians in these services. Participants could either be on drug therapy or not, and had to present stable clinical conditions at the moment of data collection.

Data were collected by trained nurses during an outpatient appointment. According to the protocol, BP was measured three times with a mercury sphygmo- manometer during evaluation, with 5-minute intervals between measurements, before the 24-hour pressure monitor was set in place.

Based on these measurements, patients were classified into two groups, according to the median of their blood pressure: controlled hypertensive patient (normal: < 140 $\mathrm{mmHg}$ for systolic BP and $<90 \mathrm{mmHg}$ for diastolic BP) and uncontrolled hypertensive patient $(\geq 140 \mathrm{mmHg}$ for systolic BP and $\geq 90 \mathrm{mmHg}$ for diastolic BP) (12).

The following patients were excluded from the study: pregnant women and patients with neoplasms, psychiatric illnesses, morbid obesity (Body Mass Index, BMI $\geq$ $35 \mathrm{~kg} / \mathrm{m}^{2}$ ), acute coronary syndrome, cardiac failure, cerebral vascular accident, congestive cardiac failure, and hypertensive crisis detected at the moment of BP measurement. The last item was characterized by symptoms such as cephalea, malaise, dizziness, blurred vision, thoracic pain, palpitations, breathing difficulty, and arterial pressure $>200 / 120 \mathrm{mmHg}(12)$. In this last case, the patient was immediately sent to the emergency room.

The 24-hour BP measurements were recorded using a continuous blood pressure monitor (model 90207 30, Spacelabs Inc, Redmond, WA, USA). The device was placed on the non-dominant upper limb of the patient between 2 p.m. and 6 p.m., and was removed 24 hours later. The device was programmed to record BP readings every 20 minutes during daytime $(6 \mathrm{a} . \mathrm{m}$. to 10 p.m.) and every 30 minutes during nighttime (10 p.m. to 6 a.m.), with a maximum of 64 readings. Only data from patients who presented enough readings were included. A satisfactory number of readings were obtained from 144 patients. Of these, eight were excluded due to technical problems in the readings. Thus, the final sample was composed of 136 patients.

Pulse Pressure was determined by subtracting mean diastolic BP from mean systolic BP. PP values greater than $53 \mathrm{mmHg}$ were considered as high risk for cardiovascular events (11). Nighttime fall in BP, characterized by a drop in systolic and diastolic BP during sleep (13), was calculated from the formula proposed by Ohkubo e cols. (14) [(mean daytime pressure - mean nighttime pressure) / (mean daytime pressure) $x$ 100]. Nighttime fall in BP was classified as moderate when values were less than $10 \%$ (non-dippers), absent when it was $0 \%$ (non-dippers), and normal when greater than or equal to $10 \%$ (dippers).

In order to characterize patients with desirable outcomes, individuals had to present at least three of the following conditions: mean 24-hour systolic BP $\geq 140$ $\mathrm{mmHg}$, mean 24-hour diastolic BP $\geq 90 \mathrm{mmHg}$, ab- 
sent or moderate nighttime fall in BP (non-dipper), or PP $>53 \mathrm{mmHg}$. In addition to this outcomes, three others were studied: 24 -hour PP $>53 \mathrm{mmHg}$; PP during sleep > $53 \mathrm{mmHg}$; and daytime $\mathrm{PP}>53 \mathrm{mmHg}$.

Two age categories were created: 29 to 59 years and 60 to 83 years. These two groups were formed based on greater alteration observed in the outcomes of individuals aged 60 years or older (15). Body Mass Index $\left(\mathrm{BMI}=\right.$ weight $/$ height $\left.^{2}\right)$ was divided into overweight $\left(\mathrm{BMI} \geq 25.0 \mathrm{~kg} / \mathrm{m}^{2}\right)$ and obesity $\left(\mathrm{BMI} \geq 30 \mathrm{~kg} / \mathrm{m}^{2}\right)$ (16). Abdominal obesity was determined according to the parameters of the National Cholesterol Education Program (17), based on the measurement of waist circumference, with cutoff points of $102 \mathrm{~cm}$ for men, and $88 \mathrm{~cm}$ for women. MS was defined by the presence of at least three of the following situations: abdominal obesity (described above), hypertriglyceridemia (triglycerides $\geq 150 \mathrm{mg} / \mathrm{dL}$ ), low HDL $(<50 \mathrm{mg} / \mathrm{dL}$ for women and $<40 \mathrm{mg} / \mathrm{dL}$ for men), arterial hypertension (systolic $\mathrm{BP} \geq 130 \mathrm{mmHg}$, diastolic $\mathrm{BP} \geq 85 \mathrm{mmHg}$, or use of antihypertensive drugs), and fasting glucose $\geq 100$ $\mathrm{mg} / \mathrm{dL}$, or use of oral antidiabetic agents/insulin (18).

In the laboratory, serum and plasma samples were analyzed using a regularly calibrated Roche COBAS MIRA PLUS chemistry analyzer. Total cholesterol, triglycerides, and glucose were determined using an enzymatic colorimetric test. Concentration of high-density lipoprotein, HDL-c, was also measured by means of an enzymatic colorimetric test, followed by precipitation of LDL-c and VLDL-c fractions with phosphotungstic acid and magnesium chloride. LDL-c concentrations were calculated by Friedewald equation, LDL-c $=$ TC (HDL- + TG $/ 5)$, in which TC represents total cholesterol, and TG, triglycerides (19). Dyslipidemia was determined by the guidelines of the National Cholesterol Education Program (17), and was detected based on the presence of at least one alteration in serum lipid values.

Bivariate logistic regression analysis was used to test the factors associated with each of these outcomes, taking into account the following independent variables: age, sex, smoking, HDL-c, LDL-c, triglycerides, total cholesterol, fasting glucose, overweight, obesity, abdominal obesity, MS, and dyslipidemia. In order to obtain the association model, a logistic regression equation was applied to each outcome of the circadian cycle of BP, using the stepwise variable selection and discarding variables with $\mathrm{p}$-values $>0.20$. In the final association model, only variables with $\mathrm{p} \leq 0.05$ were considered significant. Strength of the association between variables was estimated by odds ratio (OR) and
95\% confidence intervals (95\% CI), using the Statistical Package for Social Science (SPSS) 15.0.

The study was approved by the Research Ethics Committee of the Universidade Federal de Minas Gerais. All participants provided written, informed consent, which was freely and spontaneously obtained after all necessary explanations were given.

\section{RESULTS}

The sample studied was composed of 136 individuals, 111 women and 25 men. From these subjects, $44 \%$ were younger than 60 years of age, $58.6 \%$ were married, and $13.5 \%$ had no schooling. The vast majority were homeowners $(83.8 \%)$, and only $36.7 \%$ were employed at the time of the interview (data not shown).

Table 1 presents mean values of BP parameters obtained by 24-hour ABPM. Mean values were elevated for 24-hour systolic BP (133.57 $\mathrm{mmHg}$ ), daytime systolic BP (136.47 mmHg) and nighttime PP (53.44 $\mathrm{mmHg}$ ), when compared with normal ranges.

The prevalence of cardiovascular, metabolic and anthropometric risk factors were $52 \%$ for hypertriglyceridemia, $72.8 \%$ for low HDL, $60.3 \%$ for abdominal obesity, $58.1 \%$ for MS, $88.8 \%$ for dyslipidemia, $74.3 \%$ for overweight, and $33.8 \%$ for obesity. Women presented a higher prevalence of abdominal obesity and dyslipide$\operatorname{mia}(65.8 \%$ and $92.2 \%$, respectively), $\mathrm{p}<0.05$ (Table 2 ).

Table 1. Hemodynamic parameters determined via Ambulatory Blood Pressure Monitoring (ABPM). Belo Horizonte, Minas Gerais, Brazil, 2005

\begin{tabular}{lccccc}
\hline Blood Pressure Parameters & $\mathbf{n}$ & Mean & SD & Minimum & Maximum \\
\hline Mean Systolic BP & & & & & \\
24-hour (mmHg) & 136 & 133.57 & 13.78 & 106.00 & 168.00 \\
Daytime (mmHg) & 135 & 136.47 & 13.87 & 109.00 & 175.00 \\
$\quad$ Nighttime (mmHg) & 135 & 127.85 & 16.80 & 94.00 & 191.00 \\
Mean Diastolic BP & & & & & \\
24-hour (mmHg) & 136 & 80.80 & 8.64 & 59.00 & 106.00 \\
Daytime (mmHg) & 135 & 84.11 & 9.44 & 64.00 & 113.00 \\
Nighttime (mmHg) & 135 & 74.41 & 9.47 & 51.00 & 109.00 \\
Mean PP & & & & & \\
\hline 24-hour (mmHg) & 136 & 52.77 & 11.46 & 32.00 & 90.00 \\
Daytime (mmHg) & 135 & 52.36 & 11.49 & 31.00 & 89.00 \\
\hline Nighttime (mmHg) & 135 & 53.44 & 12.89 & 29.00 & 100.00 \\
\hline Partial or absolute fall (mmHg) & 135 & 8.61 & 11.92 & -39.00 & 41.00 \\
\hline Relative fall2 (\%) & 135 & 6.23 & 8.36 & -25.66 & 28.79 \\
\hline
\end{tabular}

BP: blood pressure; PP: pulse pressure.

${ }^{1}$ Partial or absolute fall = mean daytime systolic pressure - mean nighttime systolic pressure. ${ }^{2}$ Relative fall $=[$ (mean daytime systolic pressure - mean nighttime systolic pressure) $/$ (mean daytime systolic pressure) $\times 100]$. 
Table 3 shows the final models of the variables associated with the four outcomes, obtained with hemodynamic parameters. Being older than 60 years presented an association with each outcome (OR ranging from 2.68 to 4.74). MS also showed a strong association with 24-hour $\mathrm{PP}$, PP during sleep $>53 \mathrm{mmHg}$, and with the following groups of variables: increased 24-hour PP, non-dipper pattern, and arterial hypertension, with OR ranging from 2.29 to 4.51 . None of the other factors were significantly associated with the outcomes in the multivariate model.

\section{DISCUSSION}

The present study evaluated the relationship between metabolic disturbances and the circadian rhythm of BP, obtained by means of ABPM in hypertensive patients. From these parameters, it was possible to characterize individuals with absent or moderate nighttime fall in BP during sleep (non-dipper pattern), patients with elevated PP, and elevated mean 24-hour BP.
The presence of one or more of these factors characterized the clinical outcome. Patients who presented at least three of these conditions had high risk for target organ damage, such as ventricular hypertrophy and microalbuminuria (20). The group of hypertensive patients studied showed that mean 24-hour systolic BP mean daytime systolic BP, mean nighttime systolic $\mathrm{BP}$, and PP were above the normal range. These values were even more elevated in individuals who were 60 years old or older. Similar results were found in other studies involving elderly hypertensive patients (13,21-23).

Metabolic syndrome, diagnosed according to criteria defined by the National Cholesterol Education Program (17), and modified by Grundy and cols., was strongly associated with all parameters of circadian variation of BP evaluated in this study, except for PP during wakefulness. These results remained statistically significant, even after controlling for confounding factors, such as age and sex, in addition to other variables that were excluded from the analysis during modeling.

Table 2. Prevalence of metabolic risk factors according to sex and age. Belo Horizonte, Minas Gerais, Brazil, 2005

\begin{tabular}{|c|c|c|c|c|}
\hline \multirow{2}{*}{ Cardiovascular variables ${ }^{1}$} & Male & Female & $<60$ years & $\geq 60$ years \\
\hline & n (\%) & n (\%) & n (\%) & n (\%) \\
\hline Elevated fasting glucose (mg/dL) & $06(27.3)$ & $33(32.0)$ & $16(32.2)$ & $23(31.9)$ \\
\hline Hypertriglyceridemia (mg/dL) & $06(27.3)$ & $22(21.4)$ & $13(25.0)$ & $15(21.1)$ \\
\hline Low HDL (mg/dL) & $13(59.1)$ & $78(75.7)$ & $41(77.4)$ & $50(69.4)$ \\
\hline Elevated LDL (mg/dL) & $10(45.5)$ & $46(44.7)$ & $26(50.0)$ & $30(42.3)$ \\
\hline Hypercholesterolemia (mg/dL) & $07(31.8)$ & $52(50.5)$ & $25(48.1)$ & $34(47.9)$ \\
\hline Abdominal obesity (cm) & $09(36.0)^{2}$ & $73(65.8)^{2}$ & $36(59.0)$ & $46(61.3)$ \\
\hline Metabolic syndrome (NCEP) ${ }^{3}$ & $14(63.6)$ & $58(56.9)$ & $30(57.7)$ & $42(58.3)$ \\
\hline Dyslipidemia (NCEP) ${ }^{4}$ & $16(72.7)^{2}$ & $95(92.2)^{2}$ & $49(92.5)$ & $62(86.1)$ \\
\hline Overweight $\left(\mathrm{kg} / \mathrm{m}^{2}\right)$ & $20(80.0)$ & $81(73.0)$ & $48(78.7)$ & $53(70.7)$ \\
\hline Obesity $\left(\mathrm{kg} / \mathrm{m}^{2}\right)$ & $10(40.0)$ & $36(32.4)$ & $19(31.1)$ & $27(36.0)$ \\
\hline
\end{tabular}

${ }^{1}$ Values defined for: elevated fasting glucose $\geq 100 \mathrm{mg} / \mathrm{dL}$; hypertriglyceridemia (triglycerides $\geq 150 \mathrm{mg} / \mathrm{dL}$ ), low HDL (HDL $<50 \mathrm{mg} / \mathrm{dL}$ for women and $<40 \mathrm{mg} / \mathrm{dL}$ for men); hypercholesterolemia (total cholesterol $\geq 200 \mathrm{mg} / \mathrm{dL}$ ); abdominal obesity (WC $\geq 102 \mathrm{~cm}$ for men and $\geq 88 \mathrm{~cm}$ for women); overweight (BMI $\geq 25 \mathrm{~kg} / \mathrm{m}^{2}$ ); obesity (BMl $\geq 30 \mathrm{~kg} / \mathrm{m}^{2}$ ) (NCEP, 2001).

${ }^{2}$ Likelihood ratio. Statistically significant difference $(p<0.05)$.

${ }^{3}$ Metabolic syndrome defined by the presence of at least three of the following (cutoff values described for item 1): enlarged waist circumference, hypertriglyceridemia, low HDL, arterial hypertension (Systolic BP $\geq 130 \mathrm{mmHg}$, Diastolic BP $\geq 85 \mathrm{mmHg}$, or use of anti-hypertensive medication), and high fasting glucose (NCEP, 2001; Grundy et al., 2005).

${ }^{4}$ Dyslipidemia based on the National Cholesterol Education Program (NCEP, 2001), and detected by the presence of at least one alteration in serum lipid values.

HDL: high-density cholesterol; LDL: low-density cholesterol; BMI: body mass index; WC: waist circumference.

Table 3. Models of variables related to blood pressure circadian cycle. Belo Horizonte, Minas Gerais, Brazil, 2005

\begin{tabular}{|c|c|c|c|c|c|c|c|c|}
\hline \multirow{2}{*}{ Variables } & \multicolumn{2}{|c|}{$24 \mathrm{~h} P \mathrm{P}>53 \mathrm{mmHg}$} & \multicolumn{2}{|c|}{ Nighttime PP > 53 mmHg } & \multicolumn{2}{|c|}{ Daytime PP > 53 mmHg } & \multicolumn{2}{|c|}{ 24h PP, DIP, AHT' } \\
\hline & $\mathbf{O R}$ & $95 \% \mathrm{Cl}$ & $\mathbf{O R}$ & $95 \% \mathrm{Cl}$ & OR & $95 \% \mathrm{Cl}$ & OR & $95 \% \mathrm{Cl}$ \\
\hline Age & 4.74 & $2.118-10.652$ & 4.60 & $2.028-10.445$ & 2.68 & $1.241-5.819$ & 3.63 & $1.577-8.353$ \\
\hline Sex & 2.17 & $0.773-6.134$ & 2.37 & $0.816-6.926$ & - & - & 0.56 & $0.199-1.632$ \\
\hline Metabolic syndrome & 2.34 & $1.061-5.189$ & 2.29 & $1.037-5.096$ & - & - & 4.51 & $1.957-10.423$ \\
\hline AHT & - & - & - & - & 5.33 & $2.488-11.415$ & - & - \\
\hline
\end{tabular}

24h PP: 24-hour pulse pressure; nighttime PP: pulse pressure during sleep; Daytime PP: daytime pulse pressure; DIP: dippers; AHT: arterial hypertension.

${ }^{1}$ In this model, individuals presented at least three of the following conditions: Systolic BP $\geq 140 \mathrm{mmHg}$; Diastolic BP $\geq 90 \mathrm{mmHg}$; absent or moderate nighttime fall in BP; $24 \mathrm{~h}$ PP $>53 \mathrm{mmHg}$. 
Individuals with MS presented higher chances, ranging from 2.29 to 4.51 , of having altered circadian rhythms of BP. MS and age were not significantly associated with decreased nighttime fall in BP, when tested as an isolated outcome of altered circadian rhythm.

Several studies confirm the relationship between MS and alterations in circadian rhythm of BP (25-28), including individual components such as hypercholesterolemia, hypertriglyceridemia, low levels of HDL, insulin resistance, and abdominal obesity (24). MS is highly prevalent among patients with hypertension (25). In a study with a sample composed of 1,124 Arabs, 50\% of the non-dippers were diagnosed with MS, and $30 \%$ of the dippers were also hypertensive. In addition, in a cross-sectional study with 1,170 non-treated hypertensive individuals evaluated with 48 -hour ambulatory monitoring, PP was significantly higher in patients without nighttime fall in BP (26). Hermida and cols. showed significant associations between MS and the absence of circadian variation in daytime-nighttime BP. In a cohort study of 517 treated hypertensive patients, obesity and insulin resistance - two MS components independently influenced PP, and this effect was greater in women (28). It is presumed that there are several mediating mechanisms affecting MS for cardiovascular events. One would be caused by the hemodynamic effects of the syndrome, increasing the incidence of pre-clinic cardiovascular events and renal alterations, such as ventricular hypertrophy, microalbuminuria, reduction in aortic elasticity, and carotid arteriosclerosis (29).

Recent studies investigated nighttime fall in PP and $\mathrm{BP}$ as independent predictors of cardiovascular risk $(3,7,11,30-32)$. In a cross-sectional study conducted in Rio de Janeiro, Brazil, it was shown that PP had greater predictive power for target organ damage than nighttime fall in BP (6). The PIUMA study showed that morbidity and mortality due to cardiovascular disorders were strongly associated with 24-hour PP in apparently healthy, hypertensive individuals $(11,31)$. However, in some studies, PP was not independently associated with cardiovascular outcomes and other diseases $(30,33)$. Recently, other studies have also shown that $\mathrm{PP}$ was significantly associated with an increase in the risk for cerebral vascular accident, coronary heart disease, and congestive cardiac failure. However, predictive value was not higher than systolic BP or diastolic BP (30). Alternatively, some studies indicated that the vast majority of the elderly show isolated or predominant systolic BP elevation which, as a consequence, elevates
PP. Franklin and cols., in a study conducted with the Framingham cohort, suggested that PP could predict cardiovascular risk in older people with greater precision than systolic BP.

In the present study, it was observed that the greater the age, the greater the chance of presenting increased PP during sleep, 24-hour PP, and daytime PP, which increase the risk of developing cardiovascular diseases. These data corroborate the studies by Staessen and cols. and Pickering and cols., and shows that the loss in nighttime fall in BP, increased PP, and increased morning BP, all common among the elderly, are related to increased cardiovascular risk. In the study by Verdecchia and cols., values above $53 \mathrm{mmHg}$ were related to an almost five-fold increase in the occurrence of cardiovascular events.

Several studies suggested the use of BP during daytime, PP, and presence of nighttime fall in BP during sleep as additional stratification of cardiovascular risk among hypertensive patients who are diagnosed via sporadic BP measurements at the physician's office and not treated. However, these variables have not been employed to direct patient treatment, because there are only a few studies addressing these factors, especially in relation to PP. In this context, the present study contributes with new evidence regarding the relationship between MS and the circadian cycle of BP.

Some limitations of the present study must be mentioned. As this is a cross-sectional study, the potentially predictive variables and the outcome variables were obtained simultaneously, which makes it difficult to establish causal or temporal relationships. Studies with prospective designs would enable the observation of changes in the occurrence of cardiovascular diseases and deaths in the presence of risk factors over time. Another limitation consists of the absence of precise data regarding the drug therapy patients adopted during the study. Data concerning the presence or absence of diabetes in the individuals were unavailable and may also be an important limitation, once diabetics are more prone to develop MS. Inadequate control of BP detected in some patients also constitutes an important measurement bias. Although we studied a convenient sample, we found important relationships between MS and 24-hour BP parameters. Finally, the interpretation of the results involving gender differences must be viewed cautiously due to the higher proportion of women $(81.6 \%)$ compared to men $(18.4 \%)$ in the study.

In conclusion, our study not only showed high frequency of MS and their components in a outpatient prac- 
tice setting, but also emphasized the correlations between this syndrome and 24-hour blood pressure measurements, adjusted by age. Several mechanisms may be involved in this association. Therefore, more effective interventions in the many components and metabolic abnormalities of MS and hypertension are needed, in addition to the negative prognosis of damage to target organs.

Acknowledgments: This study was supported by a grant (CDS 275198) from Fundação de Apoio à Pesquisa do Estado de Minas Gerais (Fapemig). Gustavo Velásquez-Meléndez, Antônio Luiz Pinho Ribeiro and Gilberto Kac are research fellows from the Conselho Nacional de Desenvolvimento Científico e Tecnológico. The authors declare that there is no conflict of interest.

Disclosure: no potential conflict of interest relevant to this article was reported.

\section{REFERENCES}

1. Burr ML, Dolan E, O'Brien EW, O'Brien ET, McCormack P. The value of ambulatory blood pressure in older adults: the Dublin outcome study. Age Ageing. 2008;37(2):201-6.

2. Hermida RC. Ambulatory Blood Pressure Monitoring in the Prediction of Cardiovascular Events and Effects of Chronotherapy: Rationale and Design of the MAPEC Study. Chronobiology International. 2007;24(4):749-75.

3. Verdecchia P, Angeli F, Gattobigio R. Clinical Usefulness of Ambulatory Blood Pressure Monitoring. J Am Soc Nephrol. 2004;15:30-3.

4. Parati G, Leeuw $P$, Illyes $M$, Julius $S$, Kuwajima I, Mallion JM, et al. 2001 Consensus Conference on Ambulatory Blood Pressure Monitoring participants. Blood Press Monit. 2002;7(1):83-7.

5. Pickering TG. Ambulatory blood pressure monitoring. Curr Hypertension Repr. 2000;2:558-64.

6. Muxfeldt ES, Salles GF. Pulse pressure or dipping pattern: which one is a better cardiovascular risk marker in resistant hypertension? J Hypertens. 2008;26(5):878-84.

7. Ben Dov IZ, Kark JD, Ben-Ishay D, Mekler J, Ben-Arie L, Bursztyn M. Predictors of all-cause mortality in clinical ambulatory monitoring: unique aspects of blood pressure during sleep. Hypertension. 2007;49(6):1235-41.

8. Cuspidi C, Lonati L, Sampieri L, Michev I, Macca G, Rocanova JI, et al. Prevalence of target organ damage in treated hypertensive patients: different impact of clinic and ambulatory blood pressure control. J Hypertens. 2000;18:803-9.

9. Ohkubo T, Imai Y, Tsujii I, Nagai K, Watanabe N, Minami N, et al. Prediction of mortality by ambulatory blood pressure monitoring versus screenig blood pressure measurements: a pilot study in Ohasama. J Hypertens. 1997;15(4):357-64.

10. Verdecchia P, Schillaci G, Borgioni C, Ciucci A, Sacchi N, Batisttelli $M$, et al. Gender, day-night blood pressure changes, and left ventricular mass in essential hypertension. Dippers and peakers. Am J Hypertension. 1995;8(2):193-6.

11. Verdecchia P, Schillaci G, Borgioni C, Ciucci A, Pede S, Porcellati C. Ambulatory pulse pressure: a potent predictor of total cardiovascular risk in hypertension. Hypertension. 1998;32(6):983-8.

12. The Sixth Report of the Joint National Committee on Prevention, Detection, Evaluation, and Treatment of High Blood Pressure. National High Blood Pressure Education Program. Arch Intern Med. 1997; 157:2413-46.

13. Staessen JA, Byttobyer G, Buntinix F, Celis H, O'Brien ET, Fagards R. Antihypertensive treatment based on conventional or ambulatory blood pressure measurements: a randomized controlled trial. JAMA. 1997;278(13):1065-72.

14. Ohkubo T, Hozawa A, Nagai K, Kikuya M, Tsuji I, Ito S, et al. Prediction of stroke by ambulatory blood pressure monitoring versus screening blood pressure measurements in a general population? The Ohasama study. J Hypertens. 2000;18(7):847-54.

15. The Seventh Report of the Joint National Committee (JNC) on Prevention, Detection, Evaluation, and Treatment of High Blood Pressure. Hypertension, Hagerstown. 2003;42:1206-52.

16. World Health Organization. Consultation in obesity. Obesity: preventing and managing the global epidemic. Geneva:WHO; 1997.

17. Executive Summary of The Third Report of the National Cholesterol Education Program (NCEP) Expert Panel on Detection, Evaluation, and Treatment of High Blood Cholesterol in Adults (Adult Treatment Panel III). JAMA. 2001;285:2486-97.

18. Grundy SM, Cleeman JI, Daniels SR, Donato KA, Eckel HR, Franklin BA, et al. Diagnosis and management of the metabolic syndrome: an American Heart Association/National Heart, Lung, and Blood Institute Scientific Statement. Circulation. 2005;112(24):2735-52.

19. Friedwald WT, Levy Al, Frederickson DS. Estimation of concentrations of low density cholesterol in plasma, without use of the preparative ultracentrifuge. Clim Chem. 1972;18:499-502.

20. Steendijk P. Failure to decrease blood pressure during sleep: non-dippers are among us. The Int $\mathrm{J}$ Cardiovasc Imaging. 2006;22(2):167-9.

21. Pickering TG, Hall JE, Appel LJ, Falkner BE, Graves J, Hill MN, et al. Recommendations for blood pressure measurement in humans and experimental animals. Part 1: blood pressure measurement in humans a statement for professionals from the subcommittee of professional and public education of the American Heart Association Council on high blood pressure research. Hypertension. 2005;45:142-61.

22. Kario K, PickeringTG, UmedaY, Hoshide S, HoshideY, Morinari M, et al. Morning surge in blood pressure as predictor of silent and clinical cerebrovascular disease in elderly hypertenses. Circulation. 2003;107(10):1401-6.

23. Franklin SS, Khan AS, Wong ND, Larson MG, Levy D. Is pulse pressure useful in predicting risk for coronary heart disease? The Framingham Heart Study. Circulation. 1999;100:354-60.

24. Matz K, TatschI C, Sebek K, Dachenhausen A, Brainin M. Dyslipidemia, elevated LDL cholesterol and reduced nocturnal blood pressure dipping denote lacunar strokes occurring during nighttime. Eur J Neurol. 2004;11(11):742-8.

25. Redon J, Cífková R, Narkiewicz K. Hypertension in the metabolic syndrome: summary of the new position statement of the European Society of Hypertension. Pol Arch Med Wewn. 2009;119:255-60.

26. Hassan MO, Jaju D, Albarwani S, Al-Yahyaee S, Al-Hadabi S, Lopez-Alvarenga JC, et al. Non-dipping blood pressure in the metabolic syndrome among Arabs of the Oman family study. Obesity (Silver Spring). 2007;15:2445-53.

27. Hermida RC, Chayán L, Ayala DE, Mojón A, Domínguez MJ, Fontao MJ, et al.; Association of metabolic syndrome and blood pressure non-dipping profile in untreated hypertension. Am J Hypertens. 2009;22:307-13.

28. Vergnaud AC, Protogerou AD, LiY, Czernichow S, Vesin C, Blacher $\mathrm{J}$, et al. Pulse pressure amplification, adiposity and metabolic syndrome in subjects under chronic antihypertensive therapy: the role of heart rate. Atherosclerosis. 2008;199:222-9.

29. Mulè G, Cerasola G. The metabolic syndrome and its relationship to hypertensive target organ damage. J Clin Hypertens (Greenwich). 2006;8:195-201.

30. Mosley II WJ, Greenland P, Garside DB, Lloyd-Jones DM. Utilidade da pressão de pulso e outras medidas da pressão arterial na previsão de parâmetros cardiovasculares. Hypertension. 2007;1:27-35.

31. Madin K, lqbal P. Twenty four hour ambulatory blood pressure monitoring: a new tool for determining cardiovascular prognosis. Postgrad Med J. 2006;82(971):548-51.

32. Verdecchia P, Porcellati C, Schillaci G, Borgioni C, Ciucci A, Battistelli $M$, et al. Ambulatory blood pressure: an independent predictor of prognosis in essential hypertension. Hypertension. 1994:24:793-801.

33. Miura K, Dyer AR, Greenland P, Daviglus ML, Hill M, Liu K, et al. Pulse pressure compared with other blood pressure indexes in the prediction of 25-year cardiovascular and all-cause mortality rates: the Chicago Heart Association Detection Project in Industry Study. Hypertension. 2001;38:232-7. 